\title{
Onset of Microscopic Polyangiitis in Binephrectomied Patient on Chronic Hemodialysis - Case Report
}

\begin{abstract}
Aleksandar Jankovic ${ }^{1 *}$, Vesna Maslarevic-Radovic ${ }^{1}$, Petar Djuric ${ }^{1}$, Jelena Tosic-Dragovic ${ }^{1}$ Ana Bulatovic ${ }^{1}$, Nikola Simovic ${ }^{1}$, Milos Mitrovic ${ }^{1}$, Verica Stankovic-Popovic ${ }^{1}$, Vesna Dopudja-Pantic ${ }^{2}$, Snezana Arandjelovic ${ }^{3}$ and Nada Dimkovic ${ }^{1,4}$

${ }^{1}$ Clinical Department for Nephrology with Dialysis, University Medical Center Zvezdara, Belgrade, Serbia, ${ }^{2}$ Clinical Department for Pulmonology, University Medical Center Zvezdara, Belgrade, Serbia, ${ }^{3}$ Institute for Allergology and Immunology, Clinical Center Serbia, Belgrade, Serbia, ${ }^{4}$ Medical Faculty, Belgrade University, Belgrade, Serbia
\end{abstract}

Introduction: Microscopic polyangiitis (MPA) is one of the causes of the pulmonary-renal syndrome associated with elevated non-specific markers of inflammation and antineutrophil cytoplasmic autoantibody (ANCA) positivity in 50-75\%. De novo occurrence of the disease in patients on chronic hemodialysis (HD) has not been described.

OPEN ACCESS

Edited by:

Jixin Zhong,

Case Western Reserve University,

Reviewed by:

Xiaojing Yue,

La Jolla Institute for Allergy and Immunology, USA

Yanlin $\mathrm{He}$,

Baylor College of Medicine, USA

*Correspondence:

Aleksandar Jankovic sashajan22@yahoo.com

Specialty section:

This article was submitted to Inflammation,

a section of the journal

Frontiers in Immunology

Received: 04 December 2016 Accepted: 24 January 2017

Published: 13 February 2017

Citation:

Jankovic A, Maslarevic-Radovic V, Djuric P, Tosic-Dragovic J, Bulatovic A, Simovic N, Mitrovic M,

Stankovic-Popovic V, Dopudja-

Pantic V, Arandjelovic S and

Dimkovic N (2017) Onset of

Microscopic Polyangiitis in

Binephrectomied Patient on Chronic

Hemodialysis - Case Report.

Front. Immunol. 8:111.

doi: 10.3389/fimmu.2017.00111
Case presentation: We presented patient who developed MPO-ANCA-associated MPA with lung and musculoskeletal involvement after 4 years on regular HD due to bilateral nephrectomy. After excluding the other causes of MPO-ANCA positivity, diagnosis was confirmed even without renal biopsy. Patient received standard immunosuppression therapy and he is still in remission after 27 months.

Conclusion: The onset of immune-mediated disease could be observed even after introduction of renal replacement therapy, which may be a diagnostic problem. Early recognition and traditional immunosuppressive regiment may provide successful outcome.

Keywords: microscopic polyangiitis, chronic hemodialysis, binephrectomy, MPO-ANCA, pulmo

\section{INTRODUCTION}

Microscopic polyangiitis (MPA) is one of the antineutrophil cytoplasmic autoantibody-associated vasculitis (AAV), along with granulomatosis with polyangiitis (GPA; Wegener's) and eosinophilic granulomatosis with polyangiitis (Churg-Strauss). Antineutrophil cytoplasmic autoantibody (ANCA) may be specific for myeloperoxidase (MPO-ANCA) or for proteinase 3 (PR3-ANCA) (1).

Microscopic polyangiitis is one of the causes of the pulmonary-renal syndrome, besides Goodpasture's syndrome, systemic lupus erythematosus, and GPA (2). The onset and relapses

\footnotetext{
Abbreviations: MPA, microscopic polyangiitis; ANCA, antineutrophil cytoplasmic autoantibody; HD, hemodialysis; RRT, renal replacement therapy; MPO, antineutrophil cytoplasmic autoantibody specific for myeloperoxidase; PR3, antineutrophil cytoplasmic autoantibody specific for proteinase 3; AAV, antineutrophil cytoplasmic autoantibody-associated vasculitis; GPA, granulomatosis with polyangiitis; EGPA, eosinophilic granulomatosis with polyangiitis; SLE, systemic lupus erythematosus; ESRD, end-stage renal disease; TCC, transcellular carcinoma; PIP, proximal interphalangeal; MCP, metacarpophalangeal; CRP, $\mathrm{C}$ reactive protein; $\mathrm{pO}_{2}$, partial pressure of oxygen in arterial blood; $\mathrm{pCO}_{2}$, partial pressure of carbon dioxide in arterial blood; $\mathrm{O}_{2}$, oxygen; CT, computed tomography; PSA, prostate-specific antigen; CEA, carcinoembryonic antigen; CA 19-9, cancer antigen 19-9; AFP, alpha-fetoprotein; HBsAg, hepatitis B surface antigen; anti-HCV, anti-hepatitis C antibody; anti-HIV, anti-human immunodeficiency virus antibody; NSAID, non-steroid and anti-inflammatory drug; FEV1, forced expiratory volume in $1 \mathrm{~s} ; \mathrm{FVC}$, forced volume vital capacity; FEV1/FVC, FEV1/FVC ratio; DLCO, diffusing capacity for carbon monoxide; p-ANCA, perinuclear antineutrophil cytoplasmic antibody; c-ANCA, cytoplasmic antineutrophil cytoplasmic antibody.
} 
of systemic diseases in patient with end-stage renal disease are not so common (3). In this case report, we present the patient who developed MPO-ANCA-associated MPA with lung and musculoskeletal involvement after 4 years of regular hemodialysis (HD), and this is, as far as we could found, the first case of MPA onset in this specific population.

\section{CASE REPORT}

A 72-year-old male underwent right nephrectomy in 2006 and 2 years later total bladder cystectomy due to disseminated ureteral transcellular carcinoma. In November 2010, patients' renal function deteriorated, and after diagnosis of complicated pyelonephritis, he underwent left-side nephrectomy. Since then he was on chronic HD. He also has a history of arterial hypertension and smoking.

In June 2014, he was hospitalized due to swollen and painful wrists, proximal interphalangeal and metacarpophalangeal joints, and subfebrile temperature. Physical examination revealed lowered right basilar respiratory ton and systolic precordial murmur. Laboratory findings at admission revealed high CRP level and low hemoglobin level, despite erythropoietin therapy and iron supplementation (Table 1). Arterial blood gases pointed out acute partial respiratory insufficiency $\left(\mathrm{pO}_{2}\right.$ $7.3 \mathrm{kPa}, \mathrm{pCO}_{2} 3.4 \mathrm{kPa}, \mathrm{O}_{2}$ saturation 90\%). Chest radiography and computed tomography (CT) have shown bilateral pleural effusion (more pronounced in the right side) with subsequent compressive atelectasis and possible consolidation in lower right lung. Diagnostic pleural puncture confirmed exudation (protein level $33 \mathrm{~g} / \mathrm{L}$ ). Klebsiella-Enterobacter was isolated from the sputum culture, and patient is understood to have respiratory infection. Echocardiography revealed mild aortic

TABLE 1 | Biochemical and blood count analysis at hospital admission.

\begin{tabular}{|c|c|c|c|}
\hline Analysis & Value & Analysis & Value \\
\hline Glucose & $5.1 \mathrm{mmol} / \mathrm{L}$ & Uric acid & $359 \mu \mathrm{mol} / \mathrm{L}$ \\
\hline Cholesterol & 3.79 mmol/L & Urea & $23.3 \mathrm{mmol} / \mathrm{L}$ \\
\hline HDL cholesterol & 0.64 mmol/L & Creatinine & $735 \mu \mathrm{mol} / \mathrm{L}$ \\
\hline LDL cholesterol & 1.82 mmol/L & CK & $11 \mathrm{U} / \mathrm{L}$ \\
\hline Triglycerides & 2.93 mmol/L & Fibrinogen & $6.9 \mathrm{~g} / \mathrm{L}$ \\
\hline Albumin & $31 \mathrm{~g} / \mathrm{L}$ & $\mathrm{Fe}$ & $2.1 \mu \mathrm{mol} / \mathrm{L}$ \\
\hline protein & $66 \mathrm{~g} / \mathrm{L}$ & UIBC & $20.8 \mu \mathrm{mol} / \mathrm{L}$ \\
\hline Total bilirubin & $6.8 \mu \mathrm{mol} / \mathrm{L}$ & TIBC & $22.9 \mu \mathrm{mol} / \mathrm{L}$ \\
\hline Direct bilirubin & $1.0 \mu \mathrm{mol} / \mathrm{L}$ & Transferrin saturation & 0.09 \\
\hline AST & $12 \mathrm{U} / \mathrm{L}$ & Potassium & $5.3 \mathrm{mmol} / \mathrm{L}$ \\
\hline ALT & $11 \mathrm{U} / \mathrm{L}$ & Sodium & $137 \mathrm{mmol} / \mathrm{L}$ \\
\hline ALP & $31 \mathrm{U} / \mathrm{L}$ & Phosphorus & $1.38 \mathrm{mmol} / \mathrm{L}$ \\
\hline GGT & $16 \mathrm{U} / \mathrm{L}$ & Bicarbonates & $21 \mathrm{mmol} / \mathrm{L}$ \\
\hline $\mathrm{LDH}$ & 393 U/L & CRP & $355.6 \mathrm{mg} / \mathrm{L}$ \\
\hline $\begin{array}{l}\text { Complete blood } \\
\text { count }\end{array}$ & Value & $\begin{array}{l}\text { Leukocytic } \\
\text { formula }\end{array}$ & $\%$ \\
\hline Leukocytes & $9.95 \times 10^{9}$ & Neutrophils & 78.5 \\
\hline Erythrocytes & $3.02 \times 10^{12}$ & Lymphocytes & 8.0 \\
\hline Hemoglobin & $8.8 \mathrm{~g} / \mathrm{dL}$ & Monocytes & 2.3 \\
\hline Hematocrit & 0.29 & Eosinophils & 11.0 \\
\hline MCV & $94.7 \mathrm{fL}$ & Basophils & 0.2 \\
\hline Platelets & $284 \times 10^{9}$ & & \\
\hline
\end{tabular}

Bold font indicates the most important findings in this patients' blood analysis. stenosis and pericardial effusion $(10 \mathrm{~mm})$, without endocardial vegetations. Abdominal ultrasound was insignificant, apart form the missing kidneys. Other tests were performed in order to explain clinical status and high CRP level including bacteriology (hemocultures, coprocultures, nasal and pharyngeal swabs), tumor markers (prostate-specific antigen, carcinoembryonic antigen, CA 19-9, AFP), and markers of viral hepatitis (hepatitis B surface antigen, anti-HCV, anti-HIV), and they all were negative. Esophagogastroduodenoscopy and total colonoscopy were done, and results indicated mild erosive gastritis and diverticulosis sigmae.

Antibiotic therapy according to sputum antibiogram (Meropenem) was started together with non-steroid and antiinflammatory drug. After 14 days of antibiotic therapy, joints were still swollen and painful, CRP level was still high (139.3 mg/L), and chest radiography revealed infiltrations in middle and upper zones of the right lung and middle zone of the left lung (Figure 1). We performed respiratory function assessment which pointed out restrictive pattern of respiratory disorder [spirometry: forced expiratory volume in $1 \mathrm{~s}$ (FEV1) 55\%, FVC 56\%, FEV1/ FVC 101\%], and lung diffusion capacity (DLCO) was 59\% of anticipated and pulmonary CT angiography ruled out pulmonary thromboembolism. Results of serology analysis confirmed high levels of anti-MPO antibodies and perinuclear antineutrophil cytoplasmic antibody (p-ANCA) positivity (Table 2).

Since we could not perform kidney biopsy but have strongly positive MPO-ANCA, musculoskeletal and lung symptoms, as well as ruling out other reasons for ANCA positivity, diagnosis of MPA was established (Table 3). Specific induction therapy with intravenous cyclophosphamide (six monthly doses of $800 \mathrm{mg}$ ) and intravenous methylprednisolone (six monthly pulses with 3 days of $1 \mathrm{~g}$ ) was prescribed, followed by oral prednisone $(0.5 \mathrm{mg} / \mathrm{kg})$. After $1 \mathrm{month}$, there were no joint symptoms, CRP level was almost normal $(9.8 \mathrm{mg} / \mathrm{L})$, and arterial blood gases were recovered, and after 3 months, chest radiography was normal

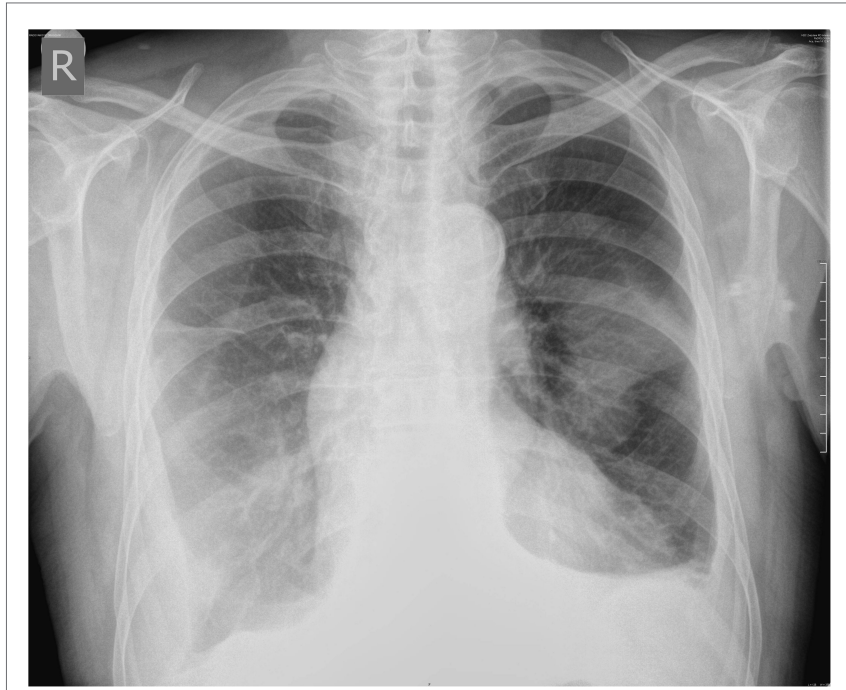

FIGURE 1 | Initial chest radiography 
TABLE 2 | Serology analysis.

\begin{tabular}{|c|c|c|c|}
\hline Analysis & & \multicolumn{2}{|l|}{ Value } \\
\hline \multicolumn{4}{|l|}{ Serology } \\
\hline & ANA (IIF) & \multicolumn{2}{|l|}{$1: 40$} \\
\hline & $\begin{array}{l}\text { p-Antineutrophil cytoplasmic } \\
\text { autoantibody (ANCA) (IIF) }\end{array}$ & \multicolumn{2}{|l|}{$1: 640$} \\
\hline & Anti-MPO at (ELISA) & \multicolumn{2}{|c|}{ 170.7 RU/ml (normal: <20 RU/mL) } \\
\hline \multicolumn{4}{|c|}{ Bold font indicates the most important findings in this patients' blood analysis. } \\
\hline \multicolumn{4}{|c|}{$\begin{array}{l}\text { TABLE } 3 \text { | Clinical manifestations of microscopic polyangiitis, overall } \\
\text { prevalence, and findings in our patient [adapted according to Ref. }(2,4,5)] \text {. }\end{array}$} \\
\hline & & & $\begin{array}{c}\text { Our } \\
\text { patient }\end{array}$ \\
\hline \multicolumn{4}{|c|}{ Constitutional manifestations } \\
\hline Fever $(55 \%$ & & & $x$ \\
\hline Malaise, fa & igue, flu-like syndrome & & $x$ \\
\hline Weight los & $(72 \%)$ & & $x$ \\
\hline \multicolumn{4}{|c|}{ Other manifestations of microscopic polyangiitis } \\
\hline \multicolumn{4}{|c|}{ Rapidly progressive glomerulonephritis (80-100\%) } \\
\hline \multicolumn{3}{|c|}{$\begin{array}{l}\text { Pulmonary involvement (alveolar hemorrhage, infiltrates, pleural } \\
\text { effusion, pleuritis, interstitial fibrosis) (25-55\%) }\end{array}$} & $x$ \\
\hline \multicolumn{4}{|c|}{ Cardiovascular (chest pain, symptoms of heart failure, pericarditis) } \\
\hline \multicolumn{4}{|c|}{$\begin{array}{l}\text { Gastrointestinal manifestations (abdominal pain, gastrointestinal } \\
\text { bleeding, colonic ulcerations) (21-58\%) }\end{array}$} \\
\hline \multicolumn{4}{|c|}{ Neurologic manifestation } \\
\hline \multicolumn{4}{|c|}{$\begin{array}{l}\text { Peripheral nervous system: mononeuritis multiplex, distal } \\
\text { symmetrical polyneuropathy (37-72\%) }\end{array}$} \\
\hline \multicolumn{4}{|c|}{$\begin{array}{l}\text { Central nervous system: cerebral hemorrhage, pachymeningitis, } \\
\text { non-hemorrhagic cerebral infarctions (17-30\%) }\end{array}$} \\
\hline \multicolumn{3}{|c|}{ Musculoskeletal involvement (arthritis, arthralgia, myalgia) } & $x$ \\
\hline \multicolumn{3}{|c|}{$\begin{array}{l}\text { Skin manifestations (palpable purpura, livedo reticularis, nodules, } \\
\text { urticaria, and skin ulcers with necrosis) (30-60\%) }\end{array}$} & \\
\hline
\end{tabular}

(Figure 2). After 6 months, control MPO-ANCA was $0.62 \mathrm{RU} /$ $\mathrm{mL}$ and $\mathrm{p}$-ANCA 1:80.

Patient is still in stable remission after 27 months of induction therapy followed by maintenance therapy (oral azathioprine $100 \mathrm{mg} /$ day).

\section{DISCUSSION}

This case report presents the patient who developed MPO-ANCAassociated MPA with lung and musculoskeletal involvement after 4 years on regular $\mathrm{HD}$.

Incident MPA patients are predominantly males (1.8:1.0) with an average age of onset between 50 and 60 years and with predominant increase of non-specific markers of inflammation (erythrocyte sedimentation rate and $\mathrm{C}$ reactive protein) and normochromic, normocytic anemia (4). Our patient was older, but he had characteristic laboratory findings. There is no test that has high diagnostic specificity for MPA, since ANCA is detected in $50-75 \%$ of patients. Among them, $90-95 \%$ have perinuclear staining pattern ( $\mathrm{p}$-ANCA) caused by antibodies against myeloperoxidase (MPO-ANCA) $(2,4)$. Therefore, renal biopsy is of a great diagnostic value.

In this patient, there were several diagnostic obstacles. Kidneys, as the most frequently involved organs, were missing so biopsy was not feasible. Also, it is unusual to expect the onset of

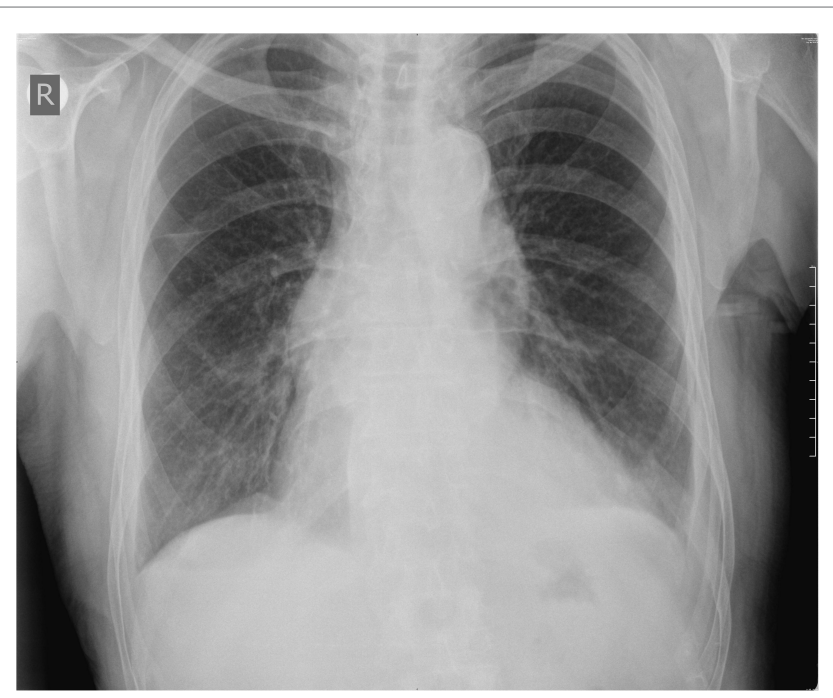

FIGURE 2 | Chest radiography after 3 months of treatment.

systemic disease in immunocompromised uremic patients who also have very rare relapses of previously diagnosed immunemediated disease (3). In addition, we had to exclude the other reasons of MPO-ANCA positivity: inflammatory bowel diseases, rheumatoid arthritis, infections (endocarditis, tuberculosis, and amebiasis), drug-induced vasculitis (hydralazine, propylthiouracil), and malignancy (6-13). Also, patients on HD may have elevated p-ANCA or c-ANCA if hemodiafiltration is used, but our patient was on standard bicarbonate dialysis (14). We also had clinical signs which correlated with these serological findings and finally, after 6 months of immunosuppression therapy, p-ANCA level was almost normal.

After the diagnosis of MPA was set, in agreement with pulmonologist and immunologist, traditional and most frequently used treatment with monthly intravenous cyclophosphamide and methylprednisolone followed by oral prednisone was introduced. This regimen is known to lower mortality in $\operatorname{AAV}(2,15)$. Good response to therapy justifies our diagnosis and patient is in stable remission after 27 months.

\section{CONCLUDING REMARKS}

In conclusion, the onset of immune-mediated disease could be observed even after introduction of renal replacement therapy, which may be a diagnostic problem. Early recognition and traditional immunosuppressive regiment may provide successful outcome.

The patient has given his written, informed consent to publish the information appearing in the article.

\section{AUTHOR CONTRIBUTIONS}

$\mathrm{AJ}$ and ND have designed the paper; VM-R, PD, JT-D, AB, NS, $\mathrm{MM}$, and VS-P have been part of every step in this patients' very 
hard and complicated diagnostic and therapeutic course and give valuable interpretation of data. All the coauthors revised paper critically and gave final approval of this version for publishing.

\section{REFERENCES}

1. Jennette JC, Falk RJ, Bacon PA, Basu N, Cid MC, Ferrario F, et al. 2012 revised International Chapel Hill Consensus Conference nomenclature of vasculitides. Arthritis Rheum (2013) 65(1):1-11. doi:10.1002/art.37715

2. Chung SA, Seo P. Microscopic polyangiitis. Rheum Dis Clin North Am (2010) 36(3):545-58. doi:10.1016/j.rdc.2010.04.003

3. Mojcik CF, Klippel JH. End-stage renal disease and systemic lupus erythematosus. Am J Med (1996) 101(1):100-7. doi:10.1016/S0002-9343(96) 00074-5

4. Guillevin L, Durand-Gasselin B, Cevallos R, Gayraud M, Lhote F, Callard $\mathrm{P}$, et al. Microscopic polyangiitis: clinical and laboratory findings in eighty-five patients. Arthritis Rheum (1999) 42(3):421-30. doi:10.1002/1529-0131(199904)42:3<421::AID-ANR5>3.0.CO;2-6

5. Guillevin L, Pagnoux C, Teixeira L. "Microscopic polyangiitis". In: Ball G, Bridges S Jr, editors. Vasculitis. Oxford: Oxford University Press (2008). p. $355-64$.

6. Oudkerk-Pool M, Ellerbroek PM, Ridwan BU, Goldschmeding R, von Blomberg BM, Peña AS, et al. Serum antineutrophil cytoplasmic autoantibodies in inflammatory bowel disease are mainly associated with ulcerative colitis: correlation between perinuclear antineutrophil cytoplasmic autoantibodies and clinical parameters, medical and surgical treatment. Gut (1993) 34(1):46-50. doi:10.1136/gut.34.1.46

7. Brimnes J, Halberg P, Wiik A, Heegaard NHH. Specificities of antineutrophil autoantibodies in patients with rheumatoid arthritis (RA). Clin Exp Immunol (1997) 110(2):250-6. doi:10.1111/j.1365-2249.1997.tb08324.x

8. Savige J, Davies D, Falk RJ, Jennette JC, Wiik A. Antineutrophil cytoplasmic antibodies and associated diseases: a review of the clinical and laboratory features. Kidney Int (2000) 57(3):846-62. doi:10.1046/j.15231755.2000.057003846.x

9. Stone JH, Talor M, Stebbing J, Uhlfelder ML, Rose NR, Carson KA, et al. Test characteristics of immunofluorescence and ELISA tests in 856 consecutive patients with possible ANCA-associated conditions. Arthritis Care Res (2000) 13(6):424-34. doi:10.1002/1529-0131(200012)13:6<424:: AID-ART14>3.0.CO;2-Q
They have ensured that all aspects of the work are accurate and have been appropriately investigated and resolved. VD-P and SA were their consultants (pulmonolgist and immunologist).

10. Bauer A, Jabs WJ, Süfke S, Maass M, Kreft B. Vasculitic purpura with antineutrophil cytoplasmic antibody-positive acute renal failure in a patient with Streptococcus bovis case and Neisseria subflava bacteremia and subacute endocarditis. Clin Nephrol (2004) 62(2):144-8. doi:10.5414/CNP62144

11. Hermann J, Demel U, Stünzner D, Daghofer E, Tilz G, Graninger W. Clinical interpretation of antineutrophil cytoplasmic antibodies: parvovirus B19 infection as a pitfall. Ann Rheum Dis (2005) 64(4):641-3. doi:10.1136/ ard.2004.024877

12. Choi HK, Merkel PA, Walker AM, Niles JL. Drug-associated antineutrophil cytoplasmic antibody-positive vasculitis: prevalence among patients with high titers of antimyeloperoxidase antibodies. Arthritis Rheum (2000) 43(2):405-13. doi:10.1002/1529-0131(200002)43:2<405::AID-ANR22>3.0. $\mathrm{CO} ; 2-5$

13. Mertz LE, Conn DL. Vasculitis associated with malignancy. Curr Opin Rheumatol (1992) 4(1):39-46.

14. Andreini B, Panichi V, Cirami C, Migliori M, De Pietro S, Taccola D, et al. ANCA in dialysis patients: a role for bioincompatibility? Int J Artif Organs (2000) 23(2):97-103.

15. Jayne D, Rasmussen N, Andrassy K, Bacon P, Tervaert JW, Dadoniené J, et al. A randomized trial of maintenance therapy for vasculitis associated with antineutrophil cytoplasmic autoantibodies. N Engl J Med (2003) 349(1):36-44. doi:10.1056/NEJMoa020286

Conflict of Interest Statement: The authors declare that the research was conducted in the absence of any commercial or financial relationships that could be construed as a potential conflict of interest.

Copyright (C) 2017 Jankovic, Maslarevic-Radovic, Djuric, Tosic-Dragovic, Bulatovic, Simovic, Mitrovic, Stankovic-Popovic, Dopudja-Pantic, Arandjelovic and Dimkovic. This is an open-access article distributed under the terms of the Creative Commons Attribution License (CC BY). The use, distribution or reproduction in other forums is permitted, provided the original author(s) or licensor are credited and that the original publication in this journal is cited, in accordance with accepted academic practice. No use, distribution or reproduction is permitted which does not comply with these terms. 